FILOLOGIJA 66, Zagreb 2016.

UDK 811.163.42'36=112.2. http://doi.org/10.21857/94k14cw2zm

Pregledni članak Primljen 3.IV.2016. Prihvaćen za tisak 24.X.2016.

Leopold Auburger

Gustav-Heinemann-Ring 32

D-81739 München

Auburger@cablemail.de

\title{
DIE KLASSIFIKATION DER VERBEN DER KROATISCHEN STANDARDLITERATURSPRACHE NACH DEM PRINZIP DER ZWEISTÄMMIGKEIT
}

\begin{abstract}
Die morphologische Klassifikation der Verben der kroatischen Standardliteratursprache nach dem Prinzip der Zweistämmigkeit von Stjepan Babić hat in der kroatischen Kroatistik als philologische Verbklassifikation mittlerweile eine feste Tradition und im Wesentlichen eine standardmäßige Geltung. Als Klassifikationskriterien dienen dabei die Art der Stamm-Endungsverbindung bei den Infinitiven und bei den indikativischen Präsensformen, sowie die Art der betreffenden Infinitiv- und Präsensendungen. Nach einem kurzen philologiegeschichtlichen Überblick wird diese Verbklassifikation hinsichtlich der Beschreibung der einzelnen Klassen und Unterklassen in ihren Einzelheiten weiter ausgearbeitet und durch typische Beispielverben konkretisiert. Zusätzlich wird als VII. Klasse eine Klasse isolierter Verben hinzugefügt. Die ausführliche Darstellung der Verbklassen wird durch eine vereinfachte Kurzdarstellung ergänzt.
\end{abstract}

\section{Einleitung}

Stjepan Babić hat seiner Wortbildungslehre eine morphologische Klassifikation der Verben der kroatischen Standardliteratursprache zugrundegelegt, die nach dem Prinzip der Infinitiv-Präsensstamm-Zweistämmigkeit geordnet ist. ${ }_{1}$ Diese Verbklassifikation hat in der kroatischen Kroatis-

\footnotetext{
${ }^{1}$ Vgl. Babić 2002:21, § 22. Die Klassifikation wird a.a.O. mit ihren sechs Klassen (I$\mathrm{VI}$; »vrste«) und mehreren Unterklassen (»razredi«) wie folgt dargestellt: I. (korijenska): 1. raz. (-Osti); 2. raz. (-Zsti); 3. raz. (-ći); 4. raz. (-reti, -rijeti, -rti); 5. raz. (-uti i ostali na -eti i -jeti); 6. raz. (-iti); 7. raz. (-ati); II. (-nuti); III. (-jeti); IV. (-iti); V. (-ati): 1. raz. (-ìm); 2. raz. (-ēm); 3. raz. (-jēm); 4. raz. (-ām); VI. (-ovati, -evati, -ivati, prez. -uj-ēm).
} 
tik als philologische Klassifikation mittlerweile eine feste Tradition und im Wesentlichen eine standardmäßige Geltung. Sie wird z. B. auch bei der Gesamtdarstellung der Prosodietypen der Verben der kroatischen Literatursprache in Vukušić-Zoričić-Grasselli-Vukušić 2007 verwendet. Üblicherweise wird sie als eine Klassifikation nach dem Prinzip der "Zweistämmigkeit« bezeichnet, da systematisch sowohl die Infinitiv- als auch die Präsensstämme berücksichtigt werden. Diese Verbklassifikation geht von der Erkenntnis aus, dass die Bildung der grammatischen Formen der Verben in der kroatischen Standardliteratursprache mit zwei Arten von Stämmen erfolgt, nämlich z. T. mit dem Infinitivstamm und z. T. mit dem Präsensstamm, die teilweise gleich, teilweise aber auch verschieden sind. Sie ist so definiert, dass sie einerseits die Art der Stamm-Endungsverbindung bei den Infinitiven und bei den indikativischen Präsensformen als Kriterium hat, andererseits aber auch die Art der betreffenden Infinitivund Präsensendungen. Diese Verbklassifikation soll hier hinsichtlich der Beschreibung der einzelnen Klassen und Unterklassen weiter ausgearbeitet werden. Zusätzlich wird als VII. Klasse eine Klasse isolierter Verben hinzugefügt. $^{2}$

\section{Allgemeine Charakteristik der Verbklassifikation nach dem Prinzip der Zweistämmigkeit}

Bei den Infinitivformen sind es die beiden Infinitivendungen $\{$-ti $\}$ oder \{-ći\}, die als eines der Klassifikationskriterien dienen, wobei durch die Endung \{-ći\} positiv nur die Unterklasse I/3 definiert wird. In den Fällen von Suppletivformen im Infinitiv und/oder Präsens vom Typ der II. Klasse bei Verben der I./3. Klasse ist für die Zuordnung zur I./3. Verbklasse allein die Existenz einer Infinitivform mit der Endung \{-ći\} entscheidend, so z. B. bei dïći, dïgnēm. Hinsichtlich der Art des Anschlusses der Endungen an den Stamm sind athematische und thematische Verben zu unterscheiden, wobei es innerhalb der letzteren solche bloß mit einem Themavokal, und

Hierbei bedeuten $» \mathrm{O} \ll$ in »-Osti« (I./1.) 'otvornik' ('Vokal') und »Z« in »-Zsti« (I./2.) 'zatvornik' ('Konsonant'). Die Beispielverben sind weggelassen.

${ }^{2}$ In Auburger 1988 habe ich zusätzlich zu den beiden Kriterien der Art der StammEndungsverbindung und der Art der Endungen bei den Infinitiven und den indikativischen Päsensformen auch noch das Kriterium der wortbildungsmäßigen Produktivität in den einzelnen Klassen verwendet (vgl. a.a.O.:142-182). Dies hatte eine andere Reihenfolge der Klassen bzw. Unterklassen als bei der jetzigen Klassifikation zur Folge. Insgesamt lassen sich die beiden Klassifikationen ganz oder teilweise wie folgt einander zuordnen: I./1.: 8; I./2.: 8; I./3.: 9; I./4.: 11; I./5.: 10; 11; 12; I./6.: 10; I./7.: 7 (zväti, zòvem/zòvēm); 12 (stäti, stänēm); II.: 3; III.: 5; IV.: 2; V./1.: 6; V./2.: 7; 13; V./3.: 7; V./4.: 1; VI.: 4; VII.: 14. 
solche mit einem zusätzlichen oder bei der Klasse II nur mit einem Suffix, das aber vokalisch auslautet, gibt. ${ }^{3}$ Die athematischen Verben sind Wurzelverben. Athematische Infinitive haben die Verben der Wurzelklassen I/1-3 und I/6; bloß thematische Infinitive haben die Verben der Klassen III; IV; V/1; V/3. Thematische Infinitive mit einem zusätzlichen oder bloß mit einem Suffix haben die Verben der Klassen II; V/2; V/4; VI. Teils athematische teils thematische Infinitive haben die Verben der Klassen I/4; I/5; I/7; VII. In der Klasse VII sind hierbei die Verben uvo./vo. bïti, uvo. jèsam, vo. büdēm; ići, ìdēm; -sūti, -spēm athematisch; htjèti, hòću, htjèdnēm hat einen thematischen Infinitiv.

Der Grund für eine Klassifikation nach dem Kriterium der Zweistämmigkeit, d. h. einerseits nach der Art der Stamm-Endungsverbindung bei den Infinitiven und bei den indikativischen Präsensformen, und andererseits nach der Art der Endungen bzw. Suffixe dieser Formen, liegt darin, dass die Bildung der grammatischen Formen der Verben mit zwei Arten von Stämmen erfolgt, nämlich z. T. mit dem Infinitivstamm und z. T. mit dem Präsensstamm. Vom Infinitivstamm werden fast ausnahmslos die folgenden Formen gebildet: der Infinitiv (bàca-ti; báci-ti); die Formen des Futurs I, die als Vollverbteil einen Infinitiv enthalten (bàca-t ću); das Aktivpartizip (bàca-o; báci-o) und damit auch die Optativformen; alle zusammengesetzten Formen, die als Vollverbteil ein Aktivpartizip enthalten, nämlich die Formen des Präteritums I/Perfekts (báci-o sam), des Präteritums II/Plusquamperfekts (bì-o sam báci-o), des Futurs II (Futurum exactum) (büdēm báci-o), sowie des Konditionals (Konjunktivs) I und Konditionals (Konjunktivs) II (bàca-o bi-h; bì-o bi-h báci-o); überwiegend die Formen des Passivpartizips (posla- ${ }^{-} n \rightarrow$ pöslān; dava- ${ }^{-} n \rightarrow$ dâvān); alle Passivformen, soweit sie als Vollverbteil ein Passivpartizip enthalten (pöslān je); die Formen des Adverbialpartizips (Gerunds) I (bàcajūći) und des Adverbialpartizips (Gerund) II (báci-vši); die Verbsubstantive mit den Suffixen $\left\{-\right.$-nje\}, $\{-j e ̄ n j e\},\{-v e ̄ n j e\}$ und $\left\{-{ }^{-c e}\right\}$, die an die jeweiligen Infinitivstämme angefügt werden (baca-' ${ }^{-}$je $\rightarrow$ bàcānje; pra-'je $\rightarrow$ pránje; bì-jēnje; dostignu-'će $\rightarrow$ dostignú-će); überwiegend die Aoristformen (báci-h); teilweise aber auch die Präsensformen (baca- ${ }^{-} \mathrm{m} \rightarrow$ bàcām; čù-jēm $\rightarrow$ čǔjēm) ${ }^{4}$ Von einem eigenen Präsensstamm werden die folgen-

\footnotetext{
${ }^{3}$ Die Themavokale als verbwurzel- oder suffixerweiternde Infinitivstammauslaute, wie z. B. -a-ti, -(j)a-ti, je-ti, -i-ti werden nicht als lexikologische Suffixe bzw. lexikologische Suffixbestandteile behandelt, sondern als eigene grammatische Suffixe, die aber als solche mit lexikologischen Suffixen in einem Bedingungszusammenhang stehen können, wie dies z. B. bei den Suffix-Themavokal-Kombinationen -áv-a-ti und -(j) ív-a-ti der Fall ist.

${ }^{4}$ Der Terminus Suffix wird hier sowohl in der üblichen Weise für wort- bzw. form-
} 
den Formen mit oder ohne morphonologisch bedingte Allomorphisierungen gebildet: überwiegend die Formen des Indikativs Präsens (jëd-ēm; kùpu-jēm) und damit auch die Formen des Imperativs der 3. Ps.; die Formen des Imperativs der 1. und 2. Ps. Sg. und Pl. sowie der 1. Ps. Pl. (bàcàj); die Formen des Imperfekts (bàc-āh); ein geringerer Teil der Aoristformen (donès-oh; ìzrek-oh); ein geringerer Teil der Formen des Passivpartizips und der mit diesen gebildeten Passivformen (doživ-(j)en $\rightarrow$ dòžĩvljen; dopust-(j)en $\rightarrow$ dòpušten); die Verbsubstantive mit den grammatischen Suffixen \{-ēnje\} und \{-(j)ēnje\}, die an die jeweiligen Präsensstämme 1. Ps. Sg. angefügt werden (bòd-ēnje; gòr-ēnje; ton-(j)ēnje $\rightarrow$ tònjēnje; bav-(j)ēnje $\rightarrow$ bävljēnje; rod-(j)ēnje $\rightarrow$ rođénje).

Die Infinitiv- und die Präsensstämme können bei der Formenbildung eine Allomorphisierung erfahren. Allomorphe entstehen hierbei insbesondere durch eine Jotierung oder Palatalisierung des betreffenden Stammauslauts, wie z. B. beim Stamm der Präsensformen prèbāc-īm, ... einerseits und jenen der Passivpartizipformen prèbāč-en, ... (prebac-(j)en $\rightarrow$ prèbāčen) andererseits. Als Ausgangsstämme für solche eventuellen Allomorphe werden hinsichtlich des Infinitivstamms der Stamm des Infinitivs und hinsichtlich des Präsensstamms der Stamm der Formen 1. bzw. 3. Ps. Sg. Indikativ Präsens genommen. Es genügt nämlich als Ausgangsformen den jeweiligen Infinitiv und die jeweilige Form 1. bzw. 3. Ps. Sg. Indikativ Präsens zu kennen, um bei einer Kenntnis der allgemeineren morphologischen Strukturen und Flexionssysteme sowie der zugehörigen morphonologischen Regeln alle übrigen Verbformen bilden zu können. Nur die prosodischen Merkmale, insbesondere jene der Akzentstelle und der Akzentqualität, verlangen zum Teil ein zusätzliches Wissen.

\section{Kurzer Überblick über die bisherigen Verbklassifikatio- nen in der Kroatistik}

Die Verbklassifikation von Stjepan Babić in Babić 2002 ist nach den dortigen Angaben eine geringfügige Modifikation einer bereits früher, nämlich in Babić 1980 vorgelegten Klassifikation. ${ }^{5}$ In Babić 1980 wird dazu auch eine knappe geschichtliche Übersicht der Verbklassifikationen in der Slavistik und speziell auch in der Kroatistik seit Anfang des 19. Jhs., nämlich seit Josef Dobrovský, gegeben. Eine knappe geschichtliche

bildende Morpheme, die keine Flexionsendungen sind, als auch für die Flexionsendungen sowie für Morphemkomplexe mit beider Art von Komponenten verwendet; dabei werden grammatische und lexikologische Suffixe unterschieden.

${ }^{5}$ Vgl. Babić 2002:21, § 22; Ham 2008:49-50. 
Übersicht der Verbklassifikationen in der älteren Slavistik, darunter speziell auch für das Kroatische und für das Serbische, enthält ferner Matešić 1970. ${ }^{6}$ Die Klassifikation, die in Matešić 1970 verwendet wird, berücksichtigt entsprechend der Themenstellung des Buches zusätzlich zu den damals bereits weitgehend traditionellen morphologischen und morphonologischen Kriterien für die jeweiligen Infinitiv- und Präsensformen auch prosodietypologische Kriterien. ${ }^{7}$

Eine umfassende Zusammenstellung und vergleichende Darstellung der wichtigsten Verbklassifikationen in der zeitgenössischen kroatischen Kroatistik bietet Jelaska 2005. Hierbei werden neben allgemeineren theoretischen und methodologischen Fragen auch die Wortbildungsproduktivität in den einzelnen Klassen, die Erkennbarkeit der jeweiligen Klassenzugehörigkeit einer konkret gegebenen einzelnen Verbform, sowie die Bestimmbarkeit der Präsensformen zu einem gegebenen Infinitiv, und umgekehrt, erörtert. Ein wichtiges Ergebnis dieser Untersuchung ist, dass es auch unabhängig von unterschiedlichen theoretisch-methodologischen Voraussetzungen mehrere relevante Kriterienkomplexe gibt, die entsprechend zu einer Mehrzahl von Verbklassifikationen führen. Ein konstanter Bestandteil dieser Kriterienkomplexe sind aber dabei morphologische und morphonologische Kriterien für die Infinitiv- und Präsensformen. $\mathrm{Zu}$ diesen können dann weitere Kriterien, wie z. B. solche der Produktivität, der Prosodie, der Computeranwendung oder didaktische Klassifikationskriterien kommen. Die Unterschiede zwischen den verschiedenen Verbklassifikationen betreffen aber im Wesentlichen, abgesehen von den erwähnten Zusatzkriterien, morphologische bzw. morphonologische Sonder- oder Randbereiche der Verbformensysteme, die jedoch erhebliche philologische Schwierigkeiten bereiten können. ${ }^{8}$

6 Vgl. a.a.O.:211.

${ }^{7}$ Eine Zuordnung der Verbklassifikation von Auburger 1988 zur Klassifikation von Matešić 1970:211 und auch von Maretić 1963:232-298 findet sich in Auburger 1988:144-145.

${ }^{8}$ Vgl. Jelaska 2005:185: »Sprezanje u hrvatskome jeziku pokazuje se i složenim gramatičkim područjem, i složenim jezikoslovnim zadatkom. Razilaženja među jezikoslovcima nisu jako velika u prototipnim pojavama, no rubne se pokazuju znatno izazovnijima jer pružaju mogućnost različitoga kategoriziranja.«

Im einzelnen werden in Jelaska 2005 die Verbklassifikationen der folgenden Werke dargestellt und miteinander verglichen:

1. Silić 1991: Die Klassifikation unterscheidet sich wesentlich von allen übrigen, da für jede Grundform eines Verbs (Infinitiv, Präsens, Imperativ, ...) ein eigener Stamm angesetzt wird, was im Vergleich mit anderen Klassifikationen zu einem Maximum an Verbklassen bzw. Verbunterklassen führt. In Silić-Pranjković 2007:42-48 sind es dann nur noch 6 Klassen mit insgesamt 29 Unterklassen, deren definitorische Kriteri- 
In der deutschen Slavistik hat August Leskien bereits bei der Darstellung der Formenbildung der Verben des Altkirchenslavischen mit einer Zweistämmigkeit als klassifikatorischer Grundlage gearbeitet, da er in den Fällen eines nicht einheitlichen Verbstamms im Formenbestand eines Verbs die Formen danach unterschied, ob sie den jeweiligen Präsensstamm der 3. Ps. Sg. oder den jeweiligen Infinitivstamm verwenden. Den Infinitivstamm bezeichnete Leskien dabei als "zweiten Stamm $« .^{9}$ In gleicher Weise hat er später in seiner Grammatik der serbo-kroatischen Sprache die Verben in solche mit einem durchgängig für alle Formen einheitlichen Verbstamm und in solche, die einen Teil ihrer Formen mit einem zweiten Stamm neben dem Stamm der Präsensform 3. Ps. Sg., nämlich mit dem vom Präsensstamm verschiedenen Infinitivstamm bilden, klassifiziert. ${ }^{10}$ Das Prinzip der Zweistämmigkeit liegt auch der in Panzer 1991 verwende-

en die angesetzten Suffixe samt Themavokale der Infinitiv- und Präsensstämme sind.

2. Babić [Jelaska] 1991: Im Gegensatz zur Klassifikation in Silić 1991 arbeitet jene in Babić [Jelaska] 1991 mit einem Minimum an Verbklassen, die hinsichtlich des jeweiligen Themavokals (/a, e, i, è/) durch jeweils nur einen, abstrakten Verbstamm definiert sind. Durch eine Vielzahl von hierarchisch geordneten, klassenspezifischen generativmorphonologischen Regeln werden davon die einzelnen Verbformen gebildet.

3. Tadić 1994: Auf Grund des computerlinguistischen Verfahrens ist die Klassifikation in Tadić 1994 der generativ-morphonologischen Klassifikation von Babić [Jelaska] 1991 ähnlich. Allerdings wird statt eines umfangreichen Regelapparates ein entsprechendes Verzeichnis von Bezugsmustern für die Generierung der jeweiligen Formen verwendet.

4. Povijesni pregled, glasovi i oblici 1991; Priručna gramatika 1979; Hrvatska gramatika 1997; Raguž 1997: In diesen Grammatiken werden Klassifikationen verwendet, die in unterschiedlicher Weise dem Typ der in der Kroatistik traditionellen zweistämmigen Verbklassifikation mit 6 Klassen, nämlich der 1. Klasse als athematischer Wurzelklasse und den übrigen Klassen als thematische Klassen, sowie mit einigen Unterklassen bei der 1. und der 5. Klasse entsprechen. Zu diesem Typ gehört dann insbesondere auch die in Babić 1980 ausgearbeitete und in Babić 2002 modifizierte Klassifikation.

5. Jelaska 2003: Hier werden in einer ersten Klassifikationsgruppe (»grupa«) je nach einem der drei Präsensendungstypen (I-III) $\{$-am $\},\{$-im $\}$, \{-em $\}$ insgesamt 9 Klassen (»vrsta «) entsprechend dem jeweiligen Infinitivstammauslaut unterschieden. Als zehnte und Nullklasse (»nulta vrsta «) wird eine Klasse der im Infinitiv athematischen Verben angesetzt. Diese Nullklasse wird dann je nach der Infinitivendung und dem Infinitivstammauslaut weiter in 8 Unterklassen differenziert; vgl. a.a.O.:179.

${ }^{9}$ Vgl. Leskien 1990 (1. Auflage: 1871):120-121.

${ }^{10}$ Vgl. Leskien 1976 (1. Auflage: 1914):458 - 46; einen einheitlichen Verbstamm haben danach z. B. »trésti« (kroat. trêsti) und »pítati« mit den Stämmen »trēs-« bzw. »pīta-«; zwei Verbstämme hat z. B. »bräti« mit dem Präsensstamm 3. Ps. Sg. »ber« als »allgemeinem « Stamm und dem Infinitivstamm »bra-« als »zweitem « Stamm (a.a.O.:459-460). 
ten Verbklassifikation zu Grunde. ${ }^{11}$ Diese Klassifikation weicht von jener in Babić 2002 erheblich ab. ${ }^{12}$ Sie soll auf alle slavischen Sprachen anwendbar sein und es ermöglichen, für alle slavischen Sprachen »die Verbalformen mit Hilfe von morphonologischen Regeln (quasi-generativ) « abzuleiten. ${ }^{13}$ Ausgearbeitet ist diese Klassifikation zuerst in Panzer 1978 worden, wo u. a. auch die Klassifikation von August Leskien hinsichtlich einer fehlenden Unterscheidung zwischen morphologischen Stammbildungs- und Endungsbestandteilen und lexikologischen Wortbildungskomponenten diskutiert wird. ${ }^{14}$

In Kunzmann-Müller 1994/1999 ist das klassifikatorische InfinitivPräsens-Zweistämmigkeitsprinzip nur sekundär berücksichtigt. Primär werden die Verben in drei »Konjugationsklassen« aufgeteilt, die durch entsprechend angesetzte Typen von Präsensendungen definiert sind. ${ }^{15}$ Diese »Konjugationsklassen « werden dann je nach Erfordernis an Hand von lexikologischen und/oder grammatischen Merkmalen der jeweiligen Infinitiv- und Präsensstämme weiter unterteilt, wobei auch Angaben zur Produktivität gemacht werden.

\section{Ausarbeitung der Verbklassifikation nach dem Prinzip der Zweistämmigkeit}

In der nachfolgenden Ausarbeitung der Verbklassifikation nach dem Prinzip der Zweistämmigkeit auf der Grundlage der Klassifikation von Stjepan Babić beziehen sich bei Angaben vom Typ »x/y « die Variable $x$ auf die Infinitivform bzw. den Infinitivstamm und y auf die Endung 1. Ps. Sg. bzw. den Stamm der jeweiligen indikativischen Präsensformen. Besonderheiten und Einzelfälle werden dabei gesondert angeführt. An weiteren besonderen Zeichen werden verwendet:

K: Konsonant

$\mathbf{K}_{\mathrm{j}}$ : jotierter Konsonant $\mathrm{K}$

N: Nasalkonsonant

V: Vokal

${ }^{11}$ Vgl. a.a.O.:XI-XIII.

${ }^{12}$ Vgl. a.a.O.:21, § 22.

${ }^{13}$ Vgl. a.a.O.:XI.

${ }^{14}$ Vgl. a.a.O.:105-107.

15 1. Aufl. 1994: 1. Konjugationsklasse: Präsensendungen -m, ... mit einem Infinitiv auf -āti oder mit Präsensformen auf -ijē-m und der zugehörigen Infinitivform auf -jeti; 2. Klasse: Präsensendungen -īm, ...; 3. Klasse: Präsensendungen -ēm, ...; vgl. a.a.O.:35-41; ebenso in der 2. Aufl. 1999. 
$\operatorname{Inf}_{\mathbf{w}^{\prime}} ; \mathbf{a}_{\mathbf{w}}$ : Infinitiv bzw. Infinitivstammauslaut /a/ von Verben aus einer der Wurzelklassen

-'em, -+ēm: unterschiedlicher Endungsanfang oder regressive Assimilationswirkung der Endung

(j)e: regressive Jotierungswirkung der Endung

ě, ě: kurzer und monophthongaler lautgeschichtlicher Nachfolgelaut des gemeinslavischen Jat als Themavokal des Infinitivstamms mit regressiver Palatalisierungswirkung bzw. bei vorausgehendem /1/ oder /n/ Jotierungswirkung $(\rightarrow / \mathbf{l j} /, / \mathbf{n j} /)$.

\subsection{Die einzelnen Verbklassen ${ }^{16}$}

\section{Wurzelklasse mit sieben Unterklassen:}

Inf $_{\mathbf{w}} / \mathbf{-}^{+} \mathbf{e m} ; \mathbf{-}^{+} \mathbf{e} \mathbf{m}$

Der Infinitivstamm $\left(\operatorname{Inf}_{\mathrm{w}}\right)$ der Verben dieser Klasse, und zwar ihrer sämtlichen Unterklassen, ist (1.) als athematischer Stamm gleich der Verbwurzel oder allomorph zu dieser, oder (2.) sein Themavokal ist an eine vokallose Verbwurzel angefügt. Die indikativischen Präsensendungen 1. Ps. Sg. dieser Verben (-+em; - +ēm) lauten mit Ausnahme von möći, mògu, möžeš, ..., mögū (Unterklasse I./3.) einerseits auf -em oder -ēm aus; andererseits kann aber der Endungsanfang bzw. die regressive Assimilationswirkung der Endung auf den vorausgehenden Stammauslaut unterschiedlich sein $\left(-^{+} \mathrm{em} ;-^{+} \mathrm{e} \mathrm{em}\right)$.

I./1.: Vs-ti/d-, s-, t-, z-em, -ēm

-nije-ti/-nes-em

bösti, bòdem; jèsti, jëdēm; pâsti, pásem; cvàsti, cvàtem; grìsti, grízem; dònijeti, donèsem ${ }^{17}$

\section{I./2.:Ks-ti/b-, p-em}

grèpsti, grèbem; cr̂psti, cŕpem

I./3.: V-ći/V̌̌-, š-, ž-em, -ēm

mö-ći/mòg-u, möž-eš, ..., mòg- $\bar{u}$

Teilweise treten Suppletivstämme im Infinitiv und/oder Präsens

${ }^{16}$ Die Prosodie der Beispielverben ist entsprechend Vukušić-Zoričić-GrasselliVukušić 2007 angegeben.

17 Die Zahl der Simplicia unter den Verben der I./1. und der nachfolgenden I./2. Verbunterklasse ist relativ klein und begrenzt. Die Verwendungshäufigkeit einzelner Verben dieser Unterklassen ist aber sehr hoch (I./1.: jësti, jëdēm; pästi, pädnēm; râsti, rástem; sjësti, sjëdnēm; srësti, srëtnēm; Präfixableitungen von -vesti, -vèdem; -vesti, -vèzem; -nijeti, -nèsem). 
vom Typ der II. Verbklasse auf, z. B. dieci/dìgnēm; pòbjeći, pòbjegnuti/pòbjegnēm; aber z. B. Aorist nur: pòbjegoh, pöbježe. Für die primäre oder sekundäre Zuordnung zur I./3. Verbklasse ist in diesen Fällen allein die Existenz einer normativ primären bzw. sekundären Infinitivform mit der Endung \{-ći\} entscheidend.

pèći, pèčem; sjēći, sijéčem; vrijêći/vróí, vrršem; leeći, lëžēm; strîći, strížem; möći, mògu, möžeš, ..., mögū

\section{I./4.: re-, rije-, r-ti/r-ēm, ri-jēm}

-zreti ${ }_{2}$ (= -glëdati), -zrēm ${ }_{2}$; dòzreti, dôzrēm/(dòzrīm); zrëti 1 (= sazrijévati), zrêm $1 /$ zrïjēm/(zrîm); -drijêti, -drêm; mrijêti, mrêm; -prijeti, -prēm; -strijeti, -strēm; -ždrijeti, -ždrēm; vrëti, vrïjēm/(vrîm); triti, trêm/tärēm ${ }^{18}$

18 Die angeführten Simplicia (zrëti ${ }_{1}, \ldots$ ) bzw. nichtabgeleiteten Präfigierungsstammwörter (-zreti ${ }_{2}$ ) sind die einzigen gebräuchlichen Simplicia bzw. Stammwörter der I./4. Verbunterkklasse. Einzelne dieser Verben gehören auf Grund ihrer Präsensformen mit den Endungen -īm, ... auch zur III. Verbklasse.

Vollendete Präfixableitungen zu uvo. vrëti, vrïjēm/(vrîm) gibt es mit pre-, pro-, uza-, za- (vo. prè-, pròvreti, prè-, pròvrijēm/(prè-, pròvrīm); dazu uvo. prè-, pròvirati, prè-, pròvirēm); vo. uzàvreti und vo. zàvreti sind ohne unvollendete Entsprechungen; uvo. ìzvirati, ìzvirēm und uvo. ùvirati, ùvirēm sind ohne eine vollendete Entsprechung. Die kirchenslavische Entsprechung zu vrëti ist вьрьти.

Die Präfixableitungen von zrëti ${ }_{1}$,reifen' (= sazrijévati), zrêm/zrìjēm/(zrîm) sind von jenen mit -zreti ${ }_{2}$-zrēm als Stammwort zu unterscheiden. Das Simplex ${ }^{*}$ zrëti $_{2}$ ,(an)schauen; sehen' (= glëdati) wird in der gesamtkroatischen Standardliteratursprache nicht mehr verwendet. Aspektuell vollendete Präfixableitungen zu zrëti sind: dòzreti, dōzrēm/(dòzrīm); dazu uvo. dozrijévati, dòzrijevām; sàzreti, säzrēm/ (sàzrìm); dazu uvo. sazrijévati, sàzrijevām; ohne unvollendete Entsprechungen sind prèzreti, prëzrēm/(prèzrīm) und ùzreti, üzrēm/(ùzrīm). Vollendete Präfixableitungen zu -zrèti ${ }_{2}$ sind: nàzreti, näzrēm; dazu uvo. nàzirati, nàzirēm; obàzreti se, òbazrēm se; dazu uvo. obàzirati se, obàzirēm se; prèzreti, prèzrēm; dazu uvo. prèzirati, prèzirēm; pròzreti, prözrēm; dazu uvo. pròzirati, pròzirēm; ùzreti, üzrēm ist ohne eine unvollendete Entsprechung.

Das Simplex uvo. drijêti, drêm ,reißen' wird funktionalstilistisch nur sehr bedingt verwendet; das normativ primäre und stilistisch neutrale Verb dafür ist uvo. dèrati, dërēm aus der V./2. Verbunterklasse. Dagegen sind die vollendeten Präfixableitungen zu drijêti, drêm funktionalstilistisch neutral verwendbar, so z. B. pròdrijeti, prödrēm (uvo. pròdirati, pròdirēm) und ràzdrijeti, räzdrēm (mit gleichbedeutendem razdèrati, ràzderēm; uvo. ràzdirati, ràzdirēm).

Eine Präfixableitung zu uvo. mrijêti, mrêm ist vo. ùmrijeti, ùmrēm (uvo. ùmirati, ùmirēm); vollendete Präfixableitungen zu uvo. tr̀̀ti, trêm/tärēm sind pòtrti, pötrēm/ pòtarēm (uvo. pòtirati, pòtirēm) und sàtrti, sätrēm/sàtarēm, (uvo. sàtirati, sàtirēm).

Die Präfigierungsstammwörter -prijeti, -strijeti und -ždrijeti werden wie auch -zre$\mathrm{ti}_{2}$ in der gesamtkroatischen Standardliteratursprache als Simplicia nicht mehr verwendet. Das Simplex *ždrijêti ist durch das Verb aus der V./2. Verbunterklasse uvo. ždèrati, ždërēm ersetzt worden. Vollendete Präfixableitungen zu diesen Stammwör- 


\section{I./5.: $\mathbf{u}$-ti und die restlichen Verben auf e-ti, sowie auf $\mathbf{e}-\mathbf{t i}$ und je-ti: u-ti/u-jēm \\ čüti, čüjēm; òbuti, öbujēm \\ e-, è-, u-ti/N-ēm: e-ti/nj-(j)ēm; è-ti/m-, n-ēm; u-ti/m-ēm \\ klê-ti (se)/kùn-em (se) \\ žèti/(žnjëti), žnjêm/žänjēm; ${ }^{19}$-ēti, -mēm;20 òtēti, ötmēm; -žēti, -žmēm;"21 -čēti, -čnēm;;2 -pēti, -pnēm;; 23 -duti, -dmēem; ${ }^{24}$ nàduti (se), nädmēm (se); klêti (se), kùnem (se) \\ $K_{\mathbf{1}} \mathbf{j e}$-ti $/ K_{1} \mathbf{i}$-jēm; $K_{1} \neq / \mathbf{l}, \mathbf{n} /{ }^{25}$}

tern sind z. B. podùprijeti, pòduprēm (uvo. podùpirati, podùpirēm); ùprijeti, ùprēm (uvo. ùpirati, ùpirēm); pròstrijeti, pröstrēm (uvo. pròstirati, pròstirēm); pròždrijeti, pröždrēm (uvo. pròždirati, pròždirēm).

${ }^{19}$ Vollendete Präfixableitungen dazu sind dò-, nà-, pòžeti, pòžanjēm/pòžnjēm; unvollendete Entsprechungen dazu gibt es nicht. Die kirchenslavische Entsprechung zum Simplex ist жАти, жьнњг.

${ }^{20}$ Vollendete Präfixableitungen mit diesem Stammwort sind izùz-, obùz-, podùz-, zaùzēti, zàuzmēm (uvo. zaùzimati, zaùzimām/zaùzimljēm); ferner òtēti (se), òtmēm (se) (uvo. òtimati (se), òtimām (se)/òtimljēm (se)); preòtēti, prèotmēm; (uvo. preòtimati, preòtimām/ preòtimljēm); ùzēti, üzmēm; (uvo. ùzimati, ùzimām/ùzimljēm); uvo. poùzimati, poùzimām ist ohne eine vollendete Entsprechung. Die kirchenslavische Entsprechung zum Simplex ist ғати, имж; kirchenslavische Präfixableitungen sind възАти, възьмж; занати, заимж.

${ }^{21}$ Vollendete Präfixableitungen mit diesem Stammwort sind nà-, prò- und sàžēti, säžmēm (uvo. sàžimati, sàžimām/sàžimljēm); ferner izàžēti, ìzažmēm (uvo. izàžimati, izàžimām/izàžimljēm). Die kirchenslavische Entsprechung zu dem Stammwort, das als selbständiges Simplex in der gesamtkroatischen Standardsprache nicht mehr verwendet wird, ist жАти, жьмж.

22 Vollendete Präfixableitungen mit diesem Stammwort sind nà-, pò-, zàčēti, zäčnēm (uvo. zàčinjati, zàčinjēm); ferner otpò- und zapòčēti, zäpočnēm (uvo. zapòčinjati, zapòčinjēm). Die kirchenslavische Entsprechung zu dem Stammwort ist -члти, -чьнж; eine kirchenslavische Präfixableitung ist vo. начлти, начьнж mit uvo. начинати, начинањ.

${ }^{23}$ Vollendete Präfixableitungen mit diesem Stammwort sind nà- + (se), po- + (se), ràs-, us- + se, zàpēti (se), zäpnēm (se); (uvo. zàpinjati (se), zàpinjēm (se)); ferrner odàund razàpēti, ràzapnēm (uvo. razàpinjati, razàpinjēm). Die kirchenslavische Entsprechung zu dem Stammwort ist плти, пьнж. Das entsprechende kroatische Simplex uvo. pêti (se) wird heute in der gesamtkroatischen Standardliteratursprache kaum mehr verwendet; statt seiner gibt es das Simplex uvo. pènjati (se), pënjēm (se).

${ }^{24}$ Dieses Stammwort wird nur mehr in der Präfixableitung nàduti (se), nädmēm (se) (uvo. nàdimati (se), nàdimām (se)) verwendet. Kirchenslavisch entspricht ihm das selbständige Simplex джти, дъмж.

${ }^{25}$ Der Themavokal /je/ im Infinitivstammauslaut ist lautgeschichtlich der kurze, monophthongale Nachfolgelaut des gemeinslavischen Jat (/ě/ bzw. ausdrücklich bezeichnet /ĕ/). Er bewirkt eine regressive Palatalisierung bzw. bei einem vorausgehen$\operatorname{den} / 1 /$ oder $/ \mathrm{n} /$ eine Jotierung $(\rightarrow / \mathrm{lj} /, \rightarrow / \mathrm{nj} /$; siehe oben bei derselben Unterklasse lje-, 
bdjëti, bdïjēm; smjëti, smïjēm; -spjeti, -spijēm; ùmjeti, ùmijēm lje-, nje-ti/lj-, nj-(j)ēm

mljëti, mëljēm; žnjëti/(žèti), žnjêm/žänjēm

\section{I./6.: i-ti/i-jēm}

bìti, bïjēm; krìti, krïjēm ${ }^{26}$

\section{I./7.: $\mathrm{Ka}_{\mathrm{w}}$-ti/K-, Kn-, Kan-em, -ēm; $\mathrm{K}=/ \mathrm{d}, \mathbf{n}, \mathbf{r}, \mathrm{t}$, v/}

däti, dádem/dädnēm/(dâm); gnàti, žènēm/(gnâm); ${ }^{27}$ bräti, bèrem/ bèrēm/bërēm; präti (se), pèrem (se)/pèrēm (se)/përēm (se); stàti, stänēm; znäti, znádem/znádēm; zväti, zòvem/zòvēm ${ }^{28}$

$1 a_{w}-t i / l j-(j) e \bar{m}$

kläti, köljēm; släti, šäljēm

\section{II.:nu-ti/n-ēm}

dìgnuti, dìgnēm; gìnuti, gìnēm; krénuti, krênēm

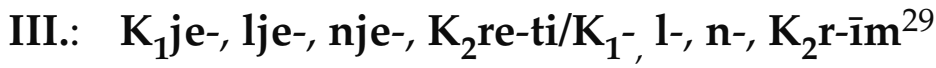

nje-ti/lj-, nj-(j)ēm), sowie bei der III. Klasse).

${ }^{26}$ An Simplicia enthält diese Unterklasse neun Verben, nämlich außer den oben angeführten noch die Verben gnjïti, gnjìjēm; lìti (se), lïjēm (se); mìti, mïjēm; pìti, pïjēm; šìti, šìjēm; vàpiti, vàpijēm/(vàpìm); vìti (se), vïjēm (se). Die kirchenslavische Entsprechung zu vàpiti ist въпити, въпињ, въпиєши.

${ }^{27}$ Das Simplex gnäti wird in der kroatischen Standardliteratursprache der Gegenwart nur noch selten und funktional-stilistisch sehr bedingt verwendet; das sprachnormativ primäre und funktionslinguistisch neutrale Verb ist gòniti, gönīm, das sprachgeschichtlich die Form mit der Vollautung zum kirchenslavischen Verb гънати bzw. zum Nachfolger des kirchenslavischen iterativen Verbs гонити darstellt. Neben гънати, жєнж, жєнєши, ... gibt es im Kirchenslavischen gleichbedeutend auch das Verb mit der Nullstufe гнати, жєнґ, жєнєши, ..., dem seinerseits das kroatische Simplex gnäti entspricht.

28 Die Simplicia der I./7. Verbunterklasse sind außer vo. däti, dádem/dädnēm/ (dâm) und vo. stäti, stänēm aspektuell alle unvollendet. Unvollendeter Aspektpartner zu vo. däti ist dávati, dâjēm, zu vo. stäti uvo. stäjati, stäjēm. Da bei däti die Präsenskonjugation dâm, ... sprachnormativ primär ist, gehört das Verb entsprechend primär zur V./4. Verbunterklasse.

$\mathrm{Zu}$ beiden Verben gibt es zahlreiche Präfixableitungen; so z. B. zu vo. stàti die Verben nà-, nè-, odù-, ò-, pò-, prè-, prì-, sà- + se, ù-, zàstati, zàstanēm (uvo. zàstajati, zàstajēm), sowie ràstati se, ràstanēm se (uvo. ràstajati se, ràstajēm se). Die beiden Verben nádati se, nâdām se und ùzdati se, ùzdām se sind aspektuell unvollendet und gehören zur V./4. Verbunterklasse.

${ }^{29}$ Zum Themavokal /je/ im Infinitivstammauslaut dieser Verben als lautgeschichtlich kurzem, monophthongalem Nachfolgelaut des gemeinslavischen Jat (/ě/ bzw. ausdrücklich bezeichnet /ě/) siehe oben bei der Unterklasse I./5. 
kípjeti, kípīm; pròbdjeti, pròbdīm; vïdjeti (se), vìdīm (se); žívjeti, žívīm; bijéljeti, bijélīm; vòljeti (se), völìm (se); cŕnjeti, cŕnīm; támnjeti, támnīm; dòzreti, dòzrīm/(dôzrēm (uvo. dozrijévati, dòzrijevām); vrëti, vrîm, ..., vrímo, ..., vrû/(vrïjēm, ...)

\section{IV.: Ki-ti/K-ìm}

báciti, bâcīm; nòsiti, nòsīm

\section{V.: $\mathbf{a}-\mathbf{t i} ; \mathbf{a} \neq \mathbf{a}_{\mathbf{w}}$}

Der Auslautvokal /a/ des Infinitivstamms ist bei allen Verben der V. Klasse ein Thema- und kein Wurzelvokal.

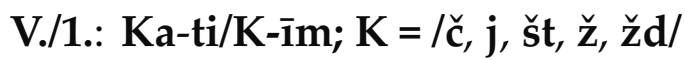 spà-ti/sp-îm ${ }^{30}$}

zvéčati, zvéčìm; bléjati, bléjìm; bòjati se, bòjīm se; šúštati, šúštìm; držati (se), držīm (se); zvíždati, zvíždīm; spàti, spîm

\footnotetext{
${ }^{30}$ Die wichtigsten weiteren präfixlosen Verben der ersten Gruppe dieser Unterklasse sind: čúčati, čúčìm 'kauern, sich niederkauern'; cvŕčati, cvŕčím 'zirpen'; dréčati, dréčìm 'plärren'; húčati, húčìm 'brausen, laut schallen'; kléčati, kléčìm ,knien, niederknien'; kríčati, kríčìm 'schreien'; mùčati, mùčìm ,schweigen'; trčati, trčìm 'laufen'; zvúčati, zvúčìm 'schallen, tönen'; stäjati, stòjīm 'stehen; kosten'; pòstojati, pòstojīm 'bestehen, dasein, existieren'; píštati, píštīm 'quieken'; pljúštati, pljúštīm '(Regen) gießen, prasseln'; tíštati, tíštìm 'plagen, (be)drücken'; tréštati, tréštīm 'krachen'; vríštati, vríštīm 'kreischen; wiehern'; bjèžati, bjèžīm 'davonlaufen, fliehen'; lèžati, lèžìm 'liegen'; réžati, réžīm ,knurren; die Zähne fletschen'; dréždati, dréždīm 'lange warten; herumhängen'.

Die Verben auf -ja-ti gehören teilweise auch zur V./2. Verbunterklasse, so z. B. brïjati, brïjēm; sïjati, sïjēm; zur V./4. Verbunterklasse gehören vjènčati (se), vjènčām (se) '(sich) verheiraten'; vráčati, vrâčām 'zäuberisch voraussagen, beschwören' und andere Verben mit einem Infinitivstammauslaut gleich jenem der Verben der V./1. Verbunterklasse.

Das unvollendete Simplex späti wird in der kroatischen Standardliteratursprache der Gegenwart im Verhältnis zu dem synonymen Verb spávati seltener verwendet. Von späti gibt es einige aspektuell vollendete Präfixableitungen, wie z. B. zàspati, zàspīm. Der Infinitivstammauslaut /a/ von späti ist ursprünglich kein Wurzel- sondern ein Themavokal, wie die kirchenslavische Entsprechung съпати (сьп-а-ти) dieses Verbs mit dem hinteren Halbvokal als Wurzelvokal zeigt.

Aspektuell sind alle Simplicia der V./2. Verbunterklasse unvollendet, ebenso alle Präfixableitungen mit den Stammwörtern -dávati und -znávati. Die Präfixableitungen mit den Stammwörtern -bljùvati, -kljùvati, -pljùvati, wie z. B. izbljùvati, ìzbljujēm; prokljùvati, pròkljujēm und is-, popljùvati, pòpljujēm, sind aspektuell vollendet.
} 


\section{V./2.: V-(j--, v-, nj-, r-)a-ti/V-(j-, j-, nj-, r-)-èm hr̀va-ti se/hr̀̀-ēm se; rèva-ti/rèv-ēm}

brïjati, brïjēm; sìjati, sìjēm; dávati, dâjēm; ${ }^{31}$-znávati, -znājēm;, ${ }^{32}$ kljùvati, kljüjēm; ${ }^{33}$ nàbirati: nàbirēm; pòčinjati, pòčinjēm; prìginjati, prìginjēm; zàklinjati, zàklinjēm; dèrati, dërēm; nàdzirati, nàdzirēm; òrati, örēm; hrvati se, hrvēm se; rèvati, rèvēm

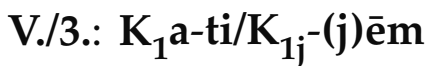

mìcati (se), mîčèm (se); tícati, tîčēm; làgati, läžēm; pomágati, pòmāžēm; díhati, dîšēm; jähati, jäšēm; skákati, skâčēm; víkati, vičēm; brìsati, brǐšèm, písati, pî̌šēm; sìsati, sǐšēm/(sìsām); dozívati, dòzīvljēm/dòzīvām); ${ }^{34}$ kázati, kâžēm; stìzati, stïžēm; vézati, vêžēm ${ }^{35}$

\section{V./4.: Ka-ti/K-ām}

bàcati, bàcām; bírati: bîrām; bívati, bîvām; darívati, dàrīvām; dāti, dâm/(dádem/dädnēm); dírati, dîrām; izazívati, izàzīvām; osnívati, òsnīvām; otkrívati, òtkrīvām; sazívati, sàzīvām; znäti, znâm/(zná-

${ }^{31}$ Das unvollendete Verb dávati hat als vollendeten Aspektpartner däti, dâm/(dádem/dädnēm); zu diesem Aspektpaar gibt es zahlreiche Präfixableitungen, so z. B. mit den Präfixen do-, iz-, o-, po-, pre-, pro-, raz-, u- + (se), za- (zadávati, zàdājēm; dazu vo. zàdati, zàdām).

Kein Verb der V./2. sondern der V./4. Verbklasse ist uvo. sazdávati, sàzdāvām (vo. sàzdati, sàzdām), dessen vollautendes Wurzelmorphem $\{$ zid $\}$ hier mit dem schwundstufigen Allomorph $\{z d\}$ vertreten ist.

32 Das Präfigierunsstammwort -znávati hat bei seinen zahlreichen Präfixableitungen als vollendeten Aspektpartner das Stammwort -znäti, -znām. Präfixableitungen gibt es z. B. mit den Präfixen do-, po-, prepo-, pri-, raspo-, raza-, sa-, upo- (uvo. upoznávati (se), upòznājēm (se); dazu vo. upòznati (se), upòznām (se); etc.).

${ }^{33}$ Zwei weitere nichtpräfigierte Verben von diesem Wortbildungstyp sind bljùvati, bljüjēm und pljùvati, pljüjēm.

${ }^{34}$ Die Präfixableitungen zu -zívati gehören zum Teil sowohl zur V./3. als auch zur V./4. Verbunterklasse: nazívati, nàzīvljēm/nàzīvām; pozívati, pòzīvljēm/pòzīvām; prizívati, prìzīvljēm/prìzīvām; prozívati, pròzīvljēm/pròzīvām. Hierbei sind aber die Präsensformen vom Typ der V./3. Verbunterklasse teilweise normativ nachrangig.

Auch andere Verben haben diese doppelte Verbklassenzugehörigkeit, wobei die betreffenden Formen zumeist normativ gleichrangig sind, so z. B. die Verben gíbati (se), gîbām (se)/gîbljēm (se); hrámati, hrâmām/hrâmljēm; käpati, käpām/käpljēm; òtimati (se), òtimām/(se)/òtimljēm (se); pljèskati, pljēskām/pljēšćēm; sìpati, sìpām/ sìpljēm; šétati (se), šêtām (se)/šêcēm (se); ùzimati, ùzimām/ùzimljēm.

35 Die Jotierungsalternation /sk/ $\leftrightarrow$ /št/ tritt nur bei dem Verb ìskati, ïštēm als sprachnormativ sekundär auf; das primäre Jotierungsergebnis ist /šć/ (ǐšćēm). Das Verb ìskati wird aber auch unabhängig davon stilistisch nur sehr bedingt verwendet. Das primäre Verb für die Hauptbedeutung von ìskati, nämlich ,suchen; fordern', ist trážiti, trâžīm. Das Jotierungsergebnis /št/ im Wurzelallomorph \{išt \} ist kirchenslavischen Ursprungs (искатн, искљ und иштж). 
dem/znádēm); zazívati, zàzīvām

VI.: K-(ov-, ev-, iv-)a-ti/Kuj-ēm

kupòvati, kùpujēm; vjërovati, vjërujēm; kraljèvati, kràljujēm; prijateljèvati, prijatèljujēm; dokazívati, dokàzujēm; upućivati, upùćujēm

VII.: Isolierte Verben

\author{
uvo./vo. bì-ti, uvo. jès-am, vo. bùd-ēm ${ }^{36}$ \\ uvo. htjè-ti, uvo. hòć-u, vo. htjêdn-ēm ${ }^{37}$ \\ î-ći, ìd-ēm ${ }^{38}$ \\ -sū-ti, -sp-ēm ${ }^{39}$
}

\begin{abstract}
${ }^{36}$ Das Verb uvo./vo. bìti, uvo. jèsam, vo. büdēm wird im Infinitiv biaspektuell verwendet, während die Präsensformen jèsam, ... nur unvollendet, büdēm, ... aspektuell nur vollendet sind. Der Stamm \{bud-\} wird außer zur Bildung aspektuell vollendeter Präsensformen auch zur Bildung der Formen des Imperativs und des Adverbialpartizips (Gerunds) I verwendet. Diese Formen sind aber aspektuell unvollendet (büdi, büdimo, bùdite; bùdūći). An Präfixbildungen zu bìti mit Zugehörigkeit zur VII. Verbklasse gibt es nur vo. zbìti se, zbüdēm se (uvo. zbívati se, zbîvām se); dagegen gehören vo. dòbiti, döbijēm, (uvo. dobívati, dòbīvām) und snèbiti se, snëbijēm se (uvo. snebívati se, snèbīvām se) zur I./6. Verbunterklasse.

37 Die Präsensformen hòću, ..., höće (3. Ps. Sgl.), ..., hòćé (3. Ps. Pl.) werden unvollendet, die Präsensformen htjëdnēm, ..., htjëdnū vollendet verwendet. Außerdem gibt es die enklitischen Formen ću, ćeš, će, ćemo, ćete, ćē (negiert: né ću, nê ćeš, nê će, nê ćemo, nê ćete, né ćē), die zumeist als Hilfsverb bei der Bildung der Futurformen verwendet werden. Die Verbwurzel, der Infinitiv- und der Präsensstamm von htjëti haben insgesamt eine mehrfache Allomorphie. An Präfixableitungen zu uvo. htjëti gibt es nur vo. pròhtjeti se, pròhtijē se/pròhtjednē se und vo. ùshtjeti, ùshtijēm/ ùshtjednēm, die beide keine unvollendete Entsprechung haben; ohne eine vollendete Entsprechung ist uvo. zahtijévati, zàhtijevām.

${ }^{38} \mathrm{Zu}$ îci, îdēm gibt es zahlreiche Präfixableitungen, deren Bildungsweise je nachdem, ob das Präfix auf einen Konsonanten oder Vokal endet, unterschiedlich ist. Bei den Präsensformen werden teilweise jotierte und nichtjotierte Präsensstämme verwendet. Die unvollendeten Entsprechungen zu den vollendeten Präfixableitungen von î́i enthalten als suppletives Stammwort -laziti. Präfixableitungen mit einer geschwundenen oder reduzierten Verbwurzel gibt es mit den Präfixen do-, iza-, na- + (se), oba-, po-, pri-, prije-, pro-, sna-, u-, za- (vo. ìzāći, ìzāđēm; vo. zâći, zâđēm; uvo. zàlaziti, zàlazìm); Präfixableitungen mit dem vollen Infinitiv- bzw. Präsensstamm gibt es mit den Präfixen iz-, na-, ob-, ot-/od-, pod-, raz- + se, s-, (vo. ìzíći, ìzīđēm, izīdēm; uvo. ìzlaziti, ìzlazīm; vo. nàíći, nàiđēm; uvo. naìlaziti, naìlazìm; sî́i, sîđēm; uvo. silaziti, silazim). Keine Präfixableitung sondern ein Kompositum mit einem Adverb ist vo. mimòići, mimòiđēm (uvo. mimoilaziti, mimoìlazīm).

${ }^{39}$ Die Präfigierungsstammwörter -sūti, -spēm, ... werden nicht als selbständige Verben verwendet ( ${ }^{*}$ sūti, ${ }^{*}$ spēm, ...). Präfixableitungen dazu gibt es mit den Präfixen dò-, ì(s)-, nà-, pò-, prè-, prò-, rà(s)-, za- und izà- sowie razà- (vo. ìsūti, ìspēm; vo. ràsūti, räspēm; vo. zàsūti, zäspēm; vo. izàsūti, ìzaspēm;); die unvollendeten Entsprechungen dazu werden von den Stammwörtern -sipati, -sipām, ... bzw. sipljēm, ... abgeleitet (uvo. zàsipati, zàsipām/zàsipljēm). Die vollendete Präfixableitung vo. izàsūti,
\end{abstract}




\subsection{Kurzdarstellung der Verbklassen}

I. Wurzelklassen: $\operatorname{Inf}_{w} /{ }^{+} \mathrm{em},-+e \bar{m}:$ I./1.: Vs-ti/d-, s-, t-, z-em, -ēm; -nije-ti/-nes-em: bösti, bòdem; jësti, jëdēm; dònijeti, donèsem; I./2.: Ks-ti/b-, p-em: grèpsti, grèbem; I./3.: V-ći/Vč-, š-, ž-em, -ēm; mö-ći/mòg-u, möžeš, ..., mög-ū: pëći, pèčem; vrijêći/vrrći, vrršem; lëći, lëžēm; möći, mògu, möžeš, ..., mögū; I./4.: re-, rije-, r-ti/r-ēm, ri-jēm: zrëti, zrêm/(zrîm); dòzreti, dözrēm/(dòzrīm); mrijêti, mrêm; vrëti, vrïjēm/(vrîm); triti, trêm/tärēm; I./5.: $u$-ti und die restlichen Verben auf e-ti, sowie auf è-ti und je-ti: u-ti/ u-jēm: čüti, čǔjēm; òbuti, öbujēm; e-, è-, u-ti/N-ēm: e-ti/nj-(j)ēm; ê-ti/m-, n-ēm; u-ti/m-ēm; klê-ti (se)/kùn-em (se): žěti (žnjëti), žnjêm/žänjēm; -ēti, -mēm; òtēti, ôtmēm; -žēti, -žmēm; -čēti, -čnēm; -pēti, -pnēm; -duti, -dmēm; nàduti (se), nädmēm (se); klêti (se), kùnem (se); $\mathrm{K}_{1} \mathrm{je}$-ti $/ \mathrm{K}_{1} \mathrm{i}-\mathrm{jēm}\left(\mathrm{K}_{1} \neq / 1\right.$, /n/): bdjëti, bdïjēm; smjëti, smïjēm; -spjeti, -spijēm; ùmjeti, ùmijēm; lje-, nje-ti/lj-, nj-(j)ēm: mljëti, mëljēm; žnjëti/(žěti), žnjêm/žänjēm; I./6.: i-ti/ijēm: bïti, bïjēm; krìti, krïjēm; vàpiti, vàpijēm/(vàpīm); I./7.: $\mathrm{Ka}_{\mathrm{w}}$-ti/K-, Kn-, Kan-em, -ēm; $(K=/ d, n, r, t, v /)$ : däti, dádem/dädnēm/(dâm); gnäti, žênēm (gnâm); bräti, bèrem/bèrēm/bërēm; präti (se), pèrem (se)/pèrēm (se)/përēm (se); stäti, stänēm; zväti, zòvem/zòvēm; $l_{\mathrm{w}}$-ti/lj-(j)ēm: kläti, köljēm; släti, šäljēm; II.: nu-ti/n-ēm: dïgnuti, dïgnēm; gìnuti, gìnēm; krénuti, krênēm;

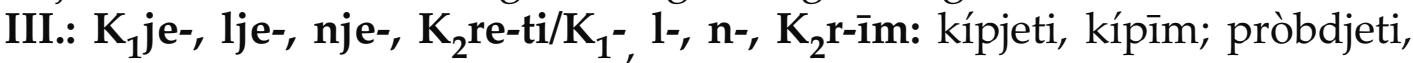
pròbdīm; vìdjeti (se), vìdīm (se); žívjeti, žívīm; bijéljeti, bijélīm; vòljeti (se), völīm (se); cŕnjeti, cŕnīm; támnjeti, támnīm; dòzreti, dòzrīm/dözrēm (uvo. dozrijévati, dòzrijevām); vrèti, vrîm, ..., vrímo, ..., vrû/(vrïjēm, ...); IV.: Ki-ti/K-īm: báciti, bâcīm; nòsiti, nösīm; V.: a-ti; $\mathbf{a} \neq \mathbf{a}_{\mathrm{w}}$ : V./1.: Ka-ti/K-īm; K = /č, j, št, ž, žd/; spä-ti/sp-îm: zvéčati, zvéčìm; bléjati, bléjīm; bòjati se, bòjīm se; šúštati, šúštìm; držati (se), držīm (se); zvíždati, zvíždīm; späti, spîm; V./2.: V-(j-, v-, nj-, r-)a-ti/V-(j-, j-, nj-, r-)-ēm; hrva-ti se/hrv-ēm se; rèva-ti/ rèv-ēm: brïjati, brïjēm; sìjati, sìjēm; dávati, dâjēm; -znávati, -znājēm; kljùvati, kljüjēm; pòčinjati, pòčinjēm; prìginjati, prìginjēm; zàklinjati, zàklinjēm; dèrati, dërēm; nàdzirati, nàdzirēm; òrati, örēm; hrvati se, hrvēm se; rèvati, rèvēm; $\mathrm{V} . / 3 .: \mathrm{K}_{1} \mathrm{a}-\mathrm{ti} / \mathrm{K}_{1 \mathrm{j}}$-(j)ēm: mìcati (se), mïčēm (se); tícati, tičēèm; làgati, läžēm; pomágati, pòmāzēem; díhati, dîšēm; jähati, jäšēm; skákati, skâčēm; víkati, viečēm; brìsati, brï̌̌ēm, písati, pîšēm; sìsati, sîšēm/(sîsām); dozívati, dòzīvljēm/(dòzīvām); kázati, kâžēm; stìzati, stǐžēm; vézati, vêžēm; V./4.: Ka-ti/K-ām: bàcati, bàcām; bívati, bîvām; darívati, dàrīvām; däti, dâm/ (dádem, dädnēm); dírati, dîrām; izazívati, izàzīvām; osnívati, òsnīvām; otkrívati, òtkrīvām; sazívati, sàzīvām; VI.: K-(ov-, ev-, iv-)a-ti/Kuj-ēm: kupòvati, kùpujēm; vjërovati, vjërujēm; kraljèvati, kràljujēm; prijateljèvati,

ìzaspēm hat keine unvollendete Entsprechung. 
prijatèljujēm; dokazívati, dokàzujēm; upućívati, upùćujēm; VII.: Isolierte Verben: bï-ti/uvo. jès-am, vo. büd-ēm; htjë-ti/uvo. hòć-u, vo. htjèdn-ēm; î-ći/ìd-ēm; -sū-ti/-sp-ēm.

\section{Literatur}

Auburger, Leopold. 1988. Verbmorphologie der kroatischen Standardsprache. Heidelberg.

Babić, Stjepan. 1980. O podjeli glagola na vrste. Jezik, časopis za kulturu hrvatskoga književnog jezika 27/5. 139-144.

Babić, Stjepan. 2002. Tvorba riječi u hrvatskome knjižeonome jeziku. Treće, poboljšano izdanje. Zagreb.

Babić [Jelaska], Zrinka. 1991. Generationi opis konjugacijskih oblika. Zagreb.

Ham, Sanda. 2008. Znanstvena djelatnost Stjepana Babića (uz 80. obljetnicu života). Babićev zbornik o 80. obljetnici života. Rasprave i članci s jezikoslovnoga znanstvenga skupa održanoga 5. i 6. svibnja 2006. u Slavonskom Brodu. Ur. Slavko Mirković. Slavonski Brod. 30-60.

Hrvatska gramatika. 1997. Hrvatska gramatika. (Barić, Eugenija; Lončarić, Mijo; Malić, Dragica; Pavešić, Slavko; Peti, Mirko; Zečević, Vesna; Znika, Marija.) II. promijenjeno izdanje. Zagreb.

Jelaska, Zrinka. 2003. Proizvodnja glagolskih oblika hrvatskoga kao stranoga jezika: od infinitiva prema prezentu. Zbornik Zagrebačke slavističke škole 2002. Zagreb. 48-63.

Jelaska, Zrinka. 2005. Glagolske vrste. Hrvatski kao drugi i strani jezik (Jelaska, Zrinka i sur.). Zagreb. 170-185.

Kunzmann-Müller, Barbara. 1994/1999. Grammatikhandbuch des Kroatischen und des Serbischen. Frankfurt a. M. 1994. 2. Aufl. unter dem Titel: Grammatikhandbuch des Kroatischen unter Einschluss des Serbischen. Frankfurt a. M. 1999.

Leskien, A[ugust]. 1976. Grammatik der serbo-kroatischen Sprache. Teil 1: Lautlehre, Stammbildung, Formenlehre. 2. Aufl. Heidelberg. (1. Auflage 1914.)

Leskien, A[ugust]. 1990. Handbuch der altbulgarischen (altkirchenslavischen) Sprache. Grammatik. Texte. Glossar. 10., von Johannes Schröpfer mit Verbesserungen und Ergänzungen versehene Auflage. Heidelberg. (1. Aufl. 1871; 5. Aufl. 1910.)

Maretić, T[omo]. 1963. Gramatika hrvatskoga ili srpskoga književnog jezika. Treće nepromijenjeno izdanje. Zagreb. (1. izd. pod naslovom Gramatika i stilistika hrvatskoga ili srpskoga književnog jezika. 1899. 2. izd. 1931.)

Matešić, Josip. 1970. Der Wortakzent in der serbokroatischen Schriftsprache. Heidelberg. 
Panzer, Baldur. 1978. Struktur und Entwicklung des slavischen Verbalstammklassensystems. Referate und Beiträge zum VIII. Internationalen Slavistenkongreß Zagreb 1978. München. 95-126.

Panzer, Baldur. 1991. Handbuch des serbokroatischen Verbs. Derivation. Heidelberg.

Povijesni pregled, glasovi i oblici. 1991. Povijesni pregled, glasovi i oblici hrvatskoga književnog jezika. Nacrti za gramatiku. (Babić, Stjepan; Brozović, Dalibor; Moguš, Milan; Pavešić, Slavko; Škarić, Ivo; Težak, Stjepan.) Zagreb.

Priručna gramatika. 1979. Priručna gramatika hrvatskoga književnog jezika. (Barić, Eugenija; Lončarić Mijo; Malić Dragica; Pavešić Slavko; Peti Mirko; Zečević Vesna; Znika Marija.) Zagreb.

Raguž, Dragutin. 1997. Praktična hrvatska gramatika. Zagreb.

Silić, Josip. 1991. Ustrojstvo glagolske osnove. Suvremena linguistika. 31/32. $3-12$.

Silić, Josip; Pranjković, Ivo. 2007. Gramatika hrvatskoga jezika za gimnazije i visoka učilišta. 2. izd. Zagreb.

Tadić, Marko. 1994. Računalna obrada morfologije hrvatskoga književnog jezi$k a$. Doktorska disertacija, Filozofski fakultet Sveučilišta u Zagrebu. Zagreb.

Vukušić, Stjepan; Zoričić, Ivan; Grasselli-Vukušić, Marija. 2007. Naglasak u hrvatskome književnom jeziku. Zagreb. 


\section{Klasifikacija glagola hrvatskoga standardnoga književnoga jezika prema načelu dvostruke osnove}

\section{Sažetak}

Morfološka klasifikacija glagola hrvatskoga književnog jezika po načelu dviju glagolskih osnova koju je Stjepan Babić 1980. godine u jednom članku objavio i u svojem velikom djelu o »Tvorbi riječi« (Babić 2002) uz sitne promjene kao osnovnu morfološku klasifikaciju primijenio, u hrvatskoj je kroatistici kao filološka klasifikacija već postala čvrstom tradicijom i standardom. Na primjer, ta se klasifikacija rabi također u sveobuhvatnoj tipologiji prozodije glagola hrvatskoga književnog jezika u isto tako velikom djelu Stjepana $\mathrm{Vu}$ kušića i dr. Naglasak u hrvatskome književnom jeziku (Vukušić-Zoričić-Grasselli-Vukušić 2007). Ta klasifikacija polazi od spoznaje da se u hrvatskom književnom jeziku morfološki oblici glagola tvore od dviju vrsti osnova, naime djelomično od infinitivne i djelomično od prezentske osnove. Obje su osnove $\mathrm{u}$ jednom dijelu glagola jednake, a u drugom različite. Kao klasifikacijski kriteriji služe s jedne strane način spajanja osnove s nastavkom kod infinitiva i kod oblika indikativnog prezenta, a s druge strane vrste dotičnih infinitivnih te prezentskih nastavaka. Glede načina se spajanja osnove s nastavkom razlikuju atematski glagoli od tematskih glagola. Potonji imaju ili samo tematski otvornik ili uz to također sufiks ili u slučaju II. vrste samo sufiks s dočetnim otvornikom. Atematski su glagoli korijenski glagoli. Poslije kratkoga se filološkopovijesnog pregleda razrađuje Babićeva glagolska klasifikacija s obzirom na formalni opis glagolskih vrsta i razreda podrobno u pojedinosti te uz oprimjerenje tipičnim glagolima. Klasifikacija se dopunjava dodavanjem VII. vrste izoliranih glagola. Iza opširnoga razrađenog prikaza klasifikacije slijedi njezin pojednostavnjen skraćen prikaz.

Ključne riječi: hrvatski standardni književni jezik, glagolska morfologija, morfološka klasifikacija glagola, načelo dviju glagolskih osnova, Babićeva glagolska klasifikacija, glagolske vrste i razredi, povijesni pregled

Key words: Croatian standard literary language, verb morphology, morphological classification of Croatian verbs, the principle of two verbal stems, the verb classification of Stjepan Babić, verb classes and subclasses, historical overview 